\title{
Erratum to: A fuzzy AHP approach to construct international hotel spa atmosphere evaluation model
}

\author{
Yen-Cheng Chen · Tung-Han Yu • \\ Pei-Ling Tsui · Ching-Sung Lee
}

Published online: 1 May 2014

C Springer Science+Business Media Dordrecht 2014

\section{Erratum to: Qual Quant (2014) 48:645-657 \\ DOI 10.1007/s11135-012-9792-2}

The original article was published with incorrect affiliation for the first author. The author's correct affiliation appears in this erratum.

The online version of the original article can be found under doi:10.1007/s11135-012-9792-2.

Y.-C. Chen

Department of Applied Science of Living, Chinese Cultural University, Taipei City, Taiwan, ROC

T.-H. Yu (凶)

Graduate Institute of Business Administration, Fu Jen Catholic University, New Taipei City, Taiwan e-mail: tunghan@gmail.com

P.-L. Tsui

Graduate Institute of Technological and Vocational Education, National Taipei University of Technology,

Taipei City, Taiwan

P.-L. Tsui

Department of Hospitality Management, National Taitung College, Taitung, Taiwan

C.-S. Lee

Department of Restaurant, Hotel and Institutional Management, Fu Jen Catholic University,

New Taipei City, Taiwan 